
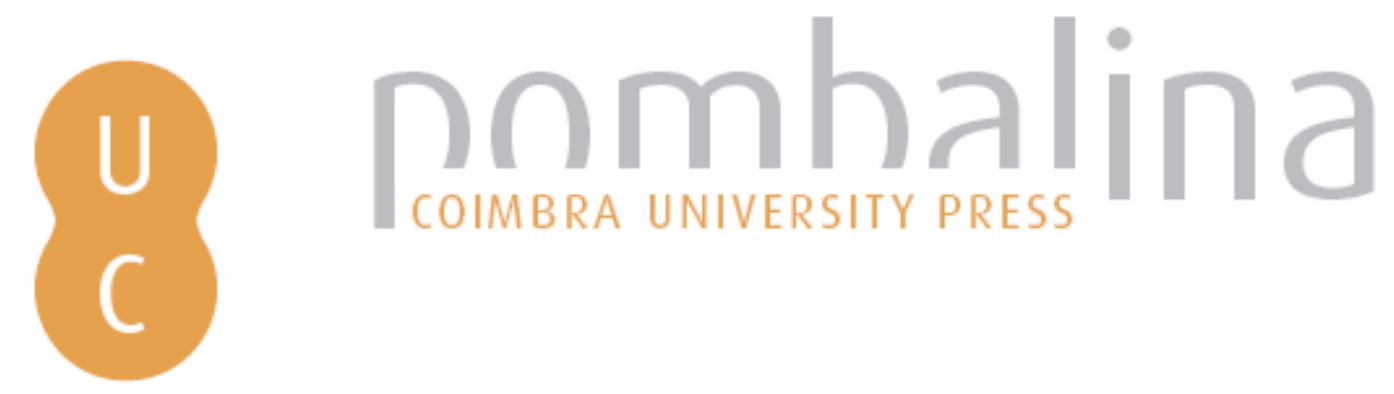

\title{
O turismo entendido como vetor estratégico em projetos educativos municipais promotores de desenvolvimento sustentado: reflexōes a propósito do caso da Figueira da Foz
}
Autor(es):
Alcoforado, Luís; Cordeiro, A. M. Rochette; Ferreira, António Gomes
Publicado por: Imprensa da Universidade de Coimbra
persistente:
URI:http://hdl.handle.net/10316.2/37366
DOI:
DOI:http://dx.doi.org/10.14195/978-989-26-0754-2_12
Accessed : $\quad$ 26-Apr-2023 11:45:51

A navegação consulta e descarregamento dos títulos inseridos nas Bibliotecas Digitais UC Digitalis, UC Pombalina e UC Impactum, pressupõem a aceitação plena e sem reservas dos Termos e Condições de Uso destas Bibliotecas Digitais, disponíveis em https://digitalis.uc.pt/pt-pt/termos.

Conforme exposto nos referidos Termos e Condições de Uso, o descarregamento de títulos de acesso restrito requer uma licença válida de autorização devendo o utilizador aceder ao(s) documento(s) a partir de um endereço de IP da instituição detentora da supramencionada licença.

Ao utilizador é apenas permitido o descarregamento para uso pessoal, pelo que o emprego do(s) título(s) descarregado(s) para outro fim, designadamente comercial, carece de autorização do respetivo autor ou editor da obra.

Na medida em que todas as obras da UC Digitalis se encontram protegidas pelo Código do Direito de Autor e Direitos Conexos e demais legislação aplicável, toda a cópia, parcial ou total, deste documento, nos casos em que é legalmente admitida, deverá conter ou fazer-se acompanhar por este aviso.

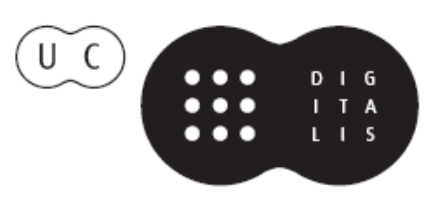


LUÍS ALCOFORADO

FPCEUC, Universidade de Coimbra

A.M. ROCHETTE CORDEIRO

CEGOT, Universidade de Coimbra

ANTÓNIO GOMES FERREIRA

FPCEUC, Universidade de Coimbra

O TURISMO ENTENDIDO COMO VETOR ESTRATÉgiCo EM PROJETOS EDUCATIVOS MUNICIPAIS PROMOTORES

DE DESENVOLVIMENTO SUSTENTADO. REFLEXÕES

a Propósito do Caso da Figueira da Foz

1. Projetos Educativos Municipais: uma maneira diferente de pensar a educação e o desenvolvimento

É cada vez mais necessário que a educação e os recursos educativos se preparem de forma a responder às novas dinâmicas de organização dos atuais tempos e espaços de vida. Nos dias de hoje, tão importante como garantir diplomas e formações específicas para um trabalho cada vez menos previsível, é indispensável ajudar todas as pessoas a organizarem as suas referências temporais, cuidando de acautelar que as atividades educativas contribuam, efetivamente, para um tempo de vida de navegação entre situações profissionais, sociais, culturais, afetivas, lúdicas e de exercício de cidadania.

Temos vindo, desta forma, a ser colocados perante novos desafios, traduzidos, na formulação de instituições internacionais com a responsabilidade da UNESCO (2004), por um entendimento de qualidade da 
educação que se deve traduzir por objetivos que priorizem a promoção do desenvolvimento cognitivo dos educandos, a garantia da aquisição dos saberes básicos necessários, o fomento de atitudes e valores de exercício de cidadania e da criação de condições propícias para o desenvolvimento afetivo e da criatividade.

Uma tal missão, afirma a UNESCO, no documento que estamos a seguir, só pode ser cumprida a partir de políticas públicas que garantam uma educação da primeira infância, igual ou superior a dois anos, um ensino básico universal para todos e uma formação de jovens e adultos que promova uma efetiva igualdade de direitos, deveres e oportunidades, ao nível social e económico, nos contextos local e global, garantindo, igualmente, o acesso de todas as pessoas à produção e usufruto dos bens culturais.

No âmbito destas políticas, será absolutamente incontornável a necessidade de desenvolver os recursos didáticos necessários, de encontrar os espaços educativos e condições físicas mais adequadas, de procurar constantemente que todos possam ter acesso aos meios tecnológicos disponíveis e que sejam formados os profissionais capazes, sendo-lhes permitida a construção de uma profissionalidade que otimize os atos educativos, favoreça as diferentes aprendizagens e potencie as transformações pessoais, sociais e contextuais, garantindo, em suma, que o conhecimento possa ganhar estatuto de bem comum, passível de ser colocado ao alcance de todos e, de forma consequente e natural, disponível para ser partilhado por todos (UNESCO, 2005).

É, também, indispensável que todos os contextos se configurem, eles próprios, como verdadeiros espaços educativos (Alcoforado, 2008). Se é pacífico aceitar o exercício da cidadania, da autonomia e da liberdade, para se ser cidadão ativo, autónomo e livre, se tem sido sublinhada a importância da experiência como base para uma ação mais eficaz e se o desenvolvimento e as aprendizagens dependem da quantidade e da qualidade das experiências e das condições socioculturais ao longo da vida, será, então, o momento de reivindicar uma responsabilidade educadora para as comunidades e a sociedade, exigindo-lhe que reconheça, exercite e desenvolva, permanentemente, além das suas funções tradicionais 
(económica, social, política e de prestação de serviços), uma função de criação e partilha generalizada de conhecimento (UNESCO, 2005).

Será importante retomar o espírito do famoso documento "Aprender a Ser", coordenado por E. Faure, do início da década de setenta do século XX, reatualizado pelo recente movimento das cidades educadoras (Marfull, 1990; Nogueras, 1990), assumindo para estas, uma intencionalidade e responsabilidade, cujo objetivo principal deverá ser a formação, promoção e desenvolvimento de todos os habitantes, construindo, desta forma, contextos sociais mais participados e solidários, convocadores do envolvimento de todos na construção de uma cidadania informada e ativa, a começar pelas comunidades de maior vizinhança.

Para que tudo isto seja possível, urge articular as políticas, as práticas comunitárias e empresariais e os projetos educativos das escolas e centros de formação, num projeto municipal alargado e integrado que envolva numa interdependência mutuamente enriquecedora, as dimensões de educação e formação e de desenvolvimento económico, social e cultural.

Mais do que pensar a educação como um problema de eficácia escolar, há necessidade de se repensar a organização da educação com o objetivo de proporcionar uma formação mais condizente com um desenvolvimento que garanta maior capacidade de ação, a partir das caraterísticas de cada território, proporcionando melhor qualidade de vida às pessoas da comunidade que o integram. Assim sendo, tanto como garantir respostas educativas formais de sucesso é indispensável olhar para o território e para a comunidade municipal como entidades vivas, que necessitam de ser estimuladas, animadas e mobilizadas.

Uma tal ideia pretende reforçar o entendimento do território como possibilidade de espaço educativo, ou, dito de outra forma, como meio envolvente, agente e conteúdo da educação, permitindo a todas as pessoas que nele interagem, uma capacidade de interpelação que deverá constituir o único fator limitativo da construção do bem-estar comum.

Nos dias de hoje, este é um dos desafios importantes que se colocam aos municípios portugueses. Não sendo, propriamente, a primeira vez que são convocados para assumir um papel mais ativo na execução de políticas de educação, tendo já responsabilidades muito significativas no 
âmbito da gestão da rede escolar e responsabilidades efetivas no desenvolvimento do ensino pré-escolar e do ensino básico, o que hoje se lhes solicita tem uma dimensão muito mais alargada.

Para além destas responsabilidades, já assumidas, no âmbito da gestão da rede e da afetação dos públicos escolares, materializadas na responsabilidade de elaborar as próprias cartas educativas, aos municípios coloca-se hoje a missão de associar a educação e o desenvolvimento integrado, num projeto articulado que possa antever um futuro de bem-estar comum, prevendo todos os recursos e os procedimentos para o alcançar.

\section{O turismo como dimensão estratégica de desenvolvimento e de um projeto educativo de incidência local}

$\mathrm{Na}$ atualidade, transformou-se quase num truísmo afirmar a utilidade estratégica do setor do turismo. Diversos estudos têm vindo a ser desenvolvidos sobre o impato deste setor nas economias locais e nacionais e todos eles confluem no reconhecimento da importância dos seus contributos para a saúde económica dos países, dos municípios e das comunidades urbanas e rurais (Hernandez \& Vaquero, 2008). Importância, desde logo, pela riqueza que gera e pelos empregos que cria, mas importância, também, pelo desafio de auto-confrontação permanente que coloca aos diferentes grupos, que interagem nesses espaços territoriais de maior identidade física e humana. Na verdade, à diversidade potencial da oferta turística, que se pode articular num determinado município, tem, forçosamente, que corresponder o desenvolvimento de atitudes e iniciativas favoráveis à criação e à promoção de produtos e momentos geradores de emoções, que exigem um envolvimento volitivo, por parte dos habitantes locais. Resulta, assim, evidente que apostar no turismo obriga a uma permanente necessidade de mudança das pessoas e das instituições, visando uma inovação contínua da qualidade da oferta.

Todo este esforço continuado de transformação deve, naturalmente, ter origem numa alargada educação de base e numa formação específica de agentes de promoção e animação, mas obrigará a que as aprendizagens se 
prolonguem e alarguem, tendo como ambiente natural de desenvolvimento o território local e as diferentes comunidades que o compõem (profissionais, sociais, culturais, de vizinhança, entre outras), entendidas como os espaços onde se estabelecem autênticas relações sociais, nomeadamente conhecimento partilhado, diálogos autênticos e experiências conjuntas.

Se é verdade que cada grupo enfrenta, em permanência e de forma obrigatória, a necessidade de empreender, em cada momento, buscas diferenciadas, tendentes a valorizar os recursos turísticos naturais e a surpreender com a criação de uma oferta renovada, a partir de produtos autênticos, será importante compreender que essa procura deve ser ancorada em novas aprendizagens sobre esses recursos e identidades culturais e sociais, dirigindo-a para mudanças provocadas pelo saber construído através de ações responsáveis. Ainda assim, para uma qualquer comunidade que anseie apostar no turismo, como dimensão significativa do seu desenvolvimento, este processo contínuo de educação e formação deverá ser alargado à generalidade das pessoas que a integram. Só na medida em que for possível ir estendendo, a todos os membros de uma comunidade, um conhecimento circunstanciado sobre o território e respetivos recursos turísticos, levando-os a amar esses bens coletivos, motivando-os para a sua conservação e defesa e tornando-os, em simultâneo, capazes de se sentirem mediadores orgulhosos do seu conhecimento e usufruto, é que ela estará preparada para o desafio de potenciar os seus produtos turísticos, com a qualidade necessária.

No entanto, se o essencial destas mudanças deve depender das aprendizagens individuais e coletivas que a comunidade pode proporcionar, torna-se fundamental tomarmos consciência de que sem políticas públicas concertadas e uma responsabilização ativa da sociedade civil, qualquer atividade de educação e formação e todas as transformações que delas pudessem advir ficariam limitadas, quer no seu desenvolvimento, quer na sua eficácia.

Com origem nas instâncias nacionais, regionais ou locais, as iniciativas políticas devem dirigir-se, primeiro, para uma lógica de articulação e complementaridade da oferta, criando condições efetivas para a sua especialização qualificada e a sua promoção articulada. Cabe aos diferen- 
tes poderes, no exercício das suas competências diferenciadas, promover a realização de estudos, mobilizar e disponibilizar recursos, definir e apoiar a criação e promoção prioritária dos tipos de turismo que reúnem efetivas probabilidades de sucesso e mobilizar os diferentes agentes para objetivos que, em simultâneo, possam ser entendidos como realistas e se constituam como retos ousados de desenvolvimento. Cabe, igualmente, a todos esses decisores, promover uma gestão previsional de qualificações e competências, articulando uma oferta formativa, inicial e contínua, dinâmica e de qualidade, capaz de se aproximar das necessidades das pessoas e das instituições, antecipando e orientando as mudanças desejáveis. Por fim será, também, da sua responsabilidade, multiplicar as potencialidades educativas dos espaços culturais e profissionais, levando ao limite os seus esforços para a construção de uma comunidade de aprendizagem.

Tornando, desta forma, o território atrativo a novos investimentos e à multiplicação dos modos de consumo turístico, será legítimo esperar das diferentes instituições da sociedade civil um envolvimento sincero e responsável que proporcione a multiplicação de iniciativas comprometidas com a valorização e bem-estar da comunidade.

Em síntese, um Projeto Educativo Municipal (PEM) deve constituir-se como um modo de ação específico, que permita organizar uma contribuição significativa, de forma metódica e progressiva, para um determinado modelo de desenvolvimento, procurando encontrar as respostas para as necessidades concretas de um território, implicando a existência prévia de objetivos e de formas de ação, utilizando os recursos disponíveis. Quando o turismo constitui uma das dimensões centrais do modelo de desenvolvimento que o município escolheu para a sua realidade em construção, ele tem de se transformar num dos pilares mais robustos do seu projeto educativo. Procuraremos compreender esta relação com o caso concreto do Município da Figueira da Foz, onde educação e turismo são colocados, inevitavelmente, numa relação interdependente, que se constitui como uma das pedras de toque mais importantes do desenvolvimento a empreender. 


\section{O turismo no Projeto Educativo Municipal da Figueira da Foz}

A necessidade de revisão do Plano de Ordenamento da Orla Costeira (POOC) e, em particular, do Plano Diretor Municipal (PDM), levou o Município da Figueira da Foz a mobilizar o contributo de um alargado número de agentes e especialistas, tendo como objetivo central a elaboração de um projeto estratégico capaz de orientar a ambição da população e dos decisores e os recursos disponíveis e mobilizáveis, com vista a definir uma ação estratégica, bem suportada, capaz de conduzir a um desenvolvimento sustentável.

Optou-se, assim, pela realização de um longo e participado processo de definição do que será o território municipal nas próximas décadas, assente numa filosofia de "Cidade Sustentável", que culminou com a apresentação do Plano Estratégico de Desenvolvimento (Figura 1), entendido como a alavanca potenciadora de todos os processos do desenvolvimento.
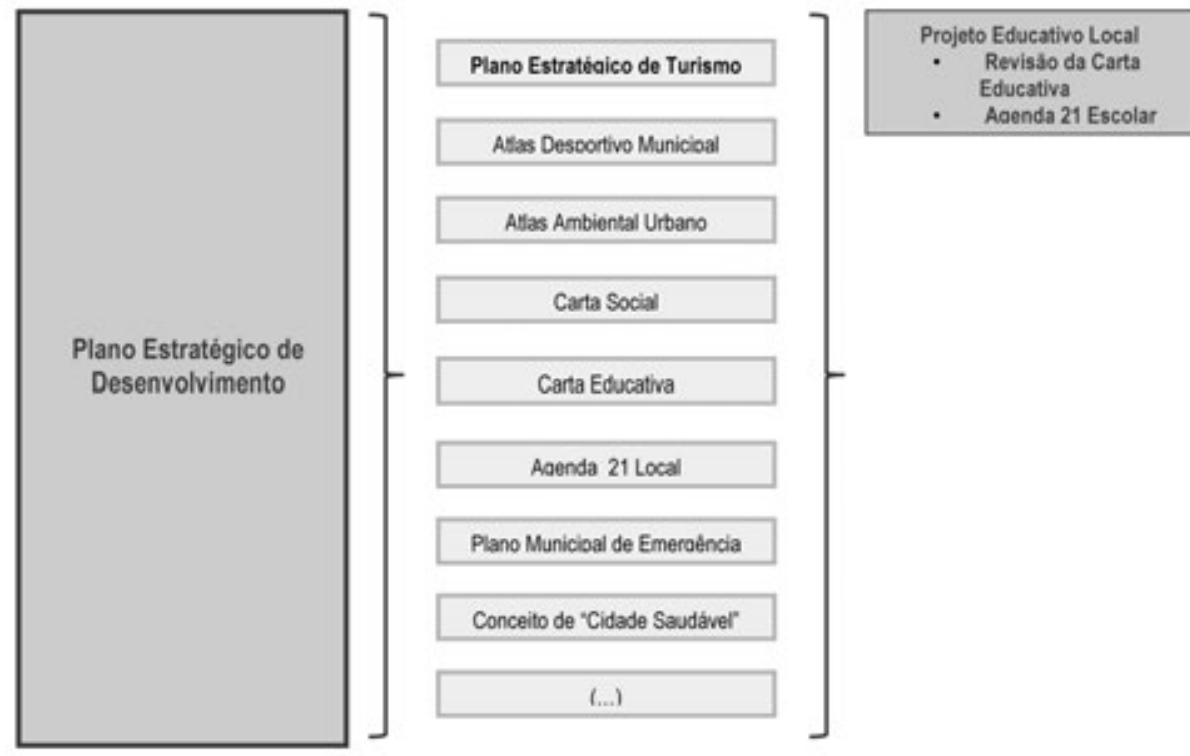

Figura 1 - As relações do Plano Estratégico de Desenvolvimento com o Projeto Educativo Municipal. 
Se, como ficou anteriormente enunciado, qualquer mudança a empreender dependerá sempre das capacidades individuais e de grupo para reagirem, anteciparem ou provocarem essas transformações, resulta claro da figura que todas as dimensões que consolidam o Plano de Desenvolvimento estratégico (PED) dependerão de uma ação articulada, em termos de iniciativas e práticas, de educação e formação que preparem todos os cidadãos para uma participação ativa e crítica. Então, concomitantemente, foi assumido por todos os participantes que o PED deveria ser acompanhado por um Projeto Educativo Municipal (PEM), destinado a dar consistência estratégica às políticas, ações concretas e projetos parcelares das diferentes instituições, ao nível da Educação e Formação ao Longo da Vida.

Num território que, desde os primórdios do turismo sol/mar em Portugal, se constituiu como um dos seus expoentes máximos, nomeadamente através da notoriedade e proventos granjeados pela praia da claridade, este cluster, assim entendido e desenvolvido segundo um modelo "mono-específico", foi, durante grande parte da segunda metade do século XX, a atividade económica que orientou, de forma dominante, as principais dimensões do seu desenvolvimento económico. No momento atual, em que se pretende despoletar um processo participado, destinado a repensar o desenvolvimento integrado do município, o turismo não poderia deixar de ter um lugar de destaque no projeto. Incluído, no entanto, num desafio de mudança paradigmática, concretizado neste contexto de análise prospetiva, ele apresenta-se já equacionado em termos de um modelo de turismo de "polarização multifuncional articulada", mais consentâneo com a atual realidade, não só do próprio cluster, mas fundamentalmente do potencial endógeno do território.

No contexto atual, também a oferta educativa, até agora direcionada para o turismo, tem refletido muito do que vêm sendo as necessidades daquele modelo "mono-específico", traduzindo os cursos existentes uma oferta, no essencial, muito direcionada para a hotelaria e a restauração. Não obstante, esta oferta, que se apresenta como algo redutora, encontra-se enquadrada nos diferentes projetos educativos que as escolas disponibilizam, observando-se atividades, cursos e projetos que desde há muito refletem as relações entre a escola e o meio e que, em muitos casos, 
tornam mais permentes as opções estratégicas que suportam o trabalho articulado que se pretende instituir, em termos futuros, entre o PEM e o novo paradigma turístico da Figueira da Foz.

Com a necessidade sentida de implementar um novo plano estratégico, construído na base do turismo sustentável, sempre entendido numa lógica de complementaridade ao sazonal turismo de sol e mar (com uma duração de, apenas, um a dois meses por ano), e com a realização de um exaustivo diagnóstico sobre as potencialidades e as debilidades do território, estão a ser identificados os caminhos alternativos de potenciação do setor turístico, muito na sequência do que se encontra referenciado no Plano Estratégico Nacional de Turismo (THR, 2006).

Parece ser incontornável que muito da complementaridade ao sol/mar passa por um turismo que possa refletir o potencial endógeno do território da Figueira da Foz, onde o "Mar", bem como as caraterísticas ambientais singulares, assumem um papel fulcral nas novas ofertas turísticas do território, nas quais o "turismo náutico" ou o "ecoturismo" (Paredes, 2007) passam a estar no centro da oferta ao longo de todo o ano, desejavelmente associados a outro tipo de possibilidades, como o turismo de "saúde", do "património material e imaterial" ou, mesmo, do turismo de "congressos/ científico" e "escolar/educativo" (Figura 2).

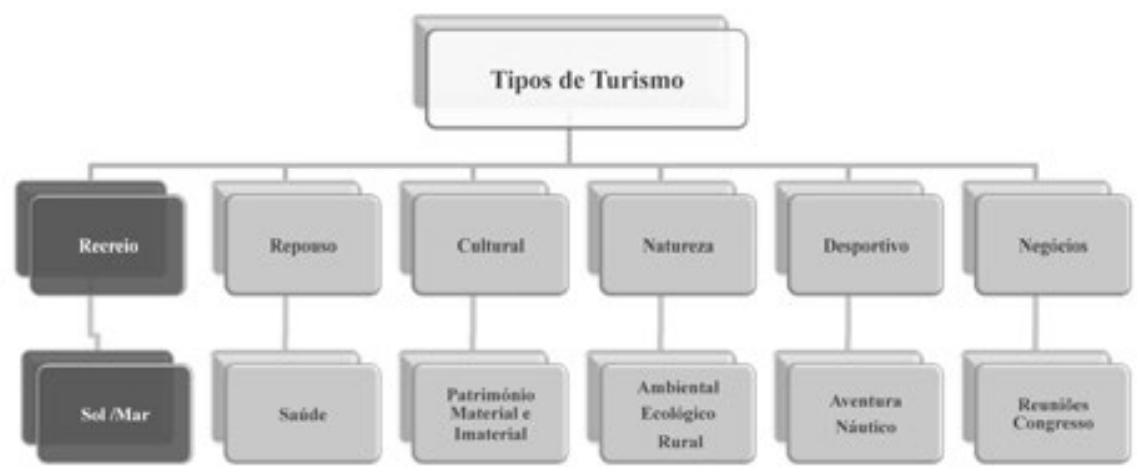

Figura 2 - Tipos de turismo da Figueira da Foz. 
O caminho que vai ser percorrido, tanto em termos de PED, como do PEM, tenderá, em cada momento, a incluir novas reflexões e contribuições, desenhando-se, assim, no quadro lógico de que apenas a caminhar é possível identificar as condições mais favoráveis e os destinos mais desejáveis e acreditando, por outro lado, que as melhores soluções não podem ser encontradas através de fórmulas mágicas, únicas ou definitivas, num processo com as caraterísticas como aquelas que aqui se pretenderam conjugar.

Nesse contexto parece ser incontornável que conhecer e amar o território, bem como o seu património material e imaterial, apresentam-se como ponto de partida para uma verdadeira discussão do PEM. Ou seja, o cidadão desde a educação pré-escolar, à idade adulta deve preparar-se para se identificar com o conhecimento do que o rodeia, sendo capaz de assumir, respeitar e promover o seu espaço físico, social, cultural e económico, de modo a que este, bem como a sua atividade turística, se assumam como parte do saber básico de uma cidadania planetária, capaz de agir responsavelmente, ao nível local.

Entende-se, assim, que na atual visão de sustentabilidade para este Município, os estabelecimentos de ensino podem e devem desempenhar um papel exemplar, contribuindo para formar cidadãos cada vez mais conscientes, capazes de interiorizar conceitos como os de sustentabilidade, ética, humanismo, cidadania e colaboração para o bem comum (Cordeiro, in press, $a ; b)$.

Parece ser inquestionável que o Plano Estratégico de Desenvolvimento, na medida em que vai desafiar a percorrer novos caminhos de crescimento, vai exigir que o PEM ouse, também, percorrer essas novas direções, abrindo espaço para um acentuado reforço do empreendorismo, da generalização das respostas inovadoras e da consolidação de uma cultura de prestação de serviços de qualidade. Cumulativamente, espera-se que ao assumir o turismo como vetor estratégico de desenvolvimento se promova uma maior maleabilidade das ofertas formativas, redirecionando-as para estas novas possibilidades de investimento público e privado, nomeadamente o turismo náutico, o ecoturismo ou mesmo o turismo desportivo, numa gestão preventiva que deverá, em simultâneo, considerar as necessidades 
da restauração e da hotelaria, quer em termos de cursos formais, quer no aproveitamento de uma opção transformadora continuada dos espaços sócio-organizacionais.

\section{Considerações finais}

Defender uma organização da educação a partir das idiossincrasias locais de um determinado território, não constitui, propriamente, um debate recente. Tal como foi sistematizado no final do século XX (Canário, 1998), a convicção das vantagens de enriquecer as políticas educativas com os contributos insubstituíveis das dinâmicas das comunidades territoriais, baseava-se num conjunto estabilizado de pressupostos, entre os quais se destacavam a constatação de que a educação não se circunscreve às escolas e a recorrente necessidade de se consagrar a política educativa local como parte integrante de uma política de desenvolvimento, também local, capaz de incrementar progressivamente a qualidade de vida das pessoas.

Quando este projeto de desenvolvimento coloca o turismo como uma das suas dimensões estruturantes, a política educativa precisa de incorporar um conjunto de necessidades e desafios que suportem o crescimento sustentado do setor. Neste contexto, os serviços públicos e as instituições da sociedade civil têm de promover uma articulação virtuosa, de forma a estimular a participação de todos. É esta a grande ambição da construção, participada, do PEM, em processo de planificação no Município da Figueira da Foz.

\section{Referências bibliográficas}

Alcoforado, J. L. M. (2008). Competências, Cidadania e Profissionalidade: limites e desafios para a construção de um modelo português de educação e formação de adultos. Dissertação de Doutoramento. Faculdade de Psicologia e de Ciências da Educação da Universidade de Coimbra. 
CANÁRIo, M. B. (1998). Construir o Projecto Educativo Local: relato de uma experiência. Lisboa: Instituto de Inovação Educacional.

Cordeiro, A. M. R. (Coord). (in press-a). Plano de Desenvolvimento dos Desportos Náuticos e Aventura, In Atlas Desportivo Municipal do Município da Figueira da Foz. Faculdade de Letras da Universidade de Coimbra.

Cordeiro, A. M. R. (Coord). (in press-b). Plano de Valorização Turística da Ilha da Morraceira, Novas Utilizações do Potencial Endógeno do Salgado da Figueira da Foz". Faculdade de Letras da Universidade de Coimbra.

Hernandez, M. G. \& Vaquero, M. (2008). Reflexiones sobre los modos de consumo turístico del património urbano. Una aproximación desde la Geografia. In J. C. Rico et al. (Edts). Como enseñar el objeto cultural (pp. 35-92). Madrid: Sílex.

Marfull, A. S. (1990). Hacia um concepto de ciudad educadora. In. Ajuntament de Barcelona. La ciudad educadora (pp. 131-140). Barcelona: Ajuntament de Barcelona.

Nogueras, J. M. T. (1990). Recorrido conceptual por la ciudad educadora. Una perspetiva filosófica. In. Ajuntament de Barcelona. La ciudad educadora (pp. 27-37). Barcelona: Ajuntament de Barcelona.

Paredes, L. C. (2007). Ecoturismo: Um Turismo Alternativo para o Baixo Mondego. Dissertação de Mestrado apresentada à Faculdade de Letras da Universidade de Coimbra, pp. 161.

THR. (2006). Proturismo - 10 Produtos Estratégicos para o Desenvolvimento do Turismo em Portugal - Turismo Náutico. Lisboa: Turismo de Portugal.

UNESCO. (2004). Educación para todos, el imperative de la calidad. Paris: UNESCO.

UNESCO. (2005). Towards Knowledge Societies. Consultado em www.unesco.org/ publishing, em 26 de novembro de 2011. 